\title{
Determining the Level of Fanaticism and Football Fanship to University Athletes
}

\author{
Oguzhan Altungul $^{1}$, M. Fatıh Karahüseyinoğlu ${ }^{1}$ \\ ${ }^{1}$ Frrat University Sports Sciences Faculty, Turkey \\ Correspondence: Oguzhan Altungul, Frrat University Sports Sciences Faculty, Turkey.
}

Received: September 6, 2017

Accepted: October 19, 2017

Online Published: October 29, 2017

doi:10.11114/jets.v5i11.2742

URL: https://doi.org/10.11114/jets.v5i11.2742

\begin{abstract}
It is the area that surrounds the broad masses of football, which includes the economic and social dimensions of the whole world. The reason why soccer is so influential is the question of the amount of football that is interested in football. The reason why soccer is so influential is the question of the amount of football that is interested in football. The concepts (fan, fanatic, and hooligan) that are included in the audience pattern are integrated with the football branch. The aim of this study, which was developed from the basic hypothesis that the opinions of university students on football advocacy / fanaticism levels will be different in terms of various variables, determines the support level of university students. In order to achieve this aim, a total of 438 students from Firat University were applied to the "Football Fanaticism Scale" consisting of 13 questions. University students are called "fanatic" in the total score 13-21, "team supporter" in the interval 22-30, and "footballer" in the range 31-52 points. $66.7 \%$ of college athletes are male and $33.3 \%$ are female. The majority (54.8\%) quit active sports and $45.2 \%$ still continue to play active sports. The percentage of active participants in team sports is $61.4 \%$. University athletes categorized themselves as "football lover" (48.2\%), "fanatic" (27.6\%) and "team supporter" (24.2\%) respectively. The average score of university athletes from FFS is; It is in the category of "football lover" with an average score of 36.68 in the range of 31-52 points. There was a meaningful relationship between university sportsmen and men, individual sportsmen and age groups in terms of team support. University sportsmen's interest in football is generally considered to be "football lover" when it is examined in terms of various variables.
\end{abstract}

Keyword: sportsman, fan, fanatic

\section{Introduction}

A sport is one of the most powerful instruments in the entertainment industry in the global world. The significance of football within the sport is so effective that it is not compared with other branches. Football is a universal phenomenon that has been followed by billions of people with mass media and many other things that have been the most contemplated on today. Football, which is the most widespread feeling of tension and joy, has now become a local, social, national and universal reality, away from its purely playful function (Eker, 2010).

It is difficult to say that all of the followers of football in different dimensions (audience, fans, fanatic, and hooligan) follow it with pleasure and enthusiasm as a game. Depending on different reasons, such as luck games, material reasons cannot be denied the existence of an immortal who prefer not to follow. Whether it is controversial or obscured by different dimensions and reasons, it is arguable that the visuality of football, which is presented to the service of sports consumers and cannot be melted by mass media for days, is arguable (Appelbaum, et al., 2012).

Football, which usually comes to mind, first when it comes to sports, is among the most controversial phenomena on the present day. The fact that football is a sporting sport that transcends universal boundaries and is loved and followed everywhere in the world has allowed it to break out of other sports. In this context football is now a part of the global reality and its reflection is the identity (Cakir and Korkmaz, 2015).

It is worth noting that there are two important actors or parties at the base of the football event. Firstly it is possible to count footballers who are the producers of football and referees, observers, fans and other instruments which are among the basic elements of soccer matches. The most basic actor of football is the consumer. It is difficult to say that the viewers are of a homogeneous structure. However, it is possible to classify the spectators in society where football culture is widely developed. The observer is also referred to as the "twelfth man". 
In football literature, the concepts of spectators, fanatics and fans are frequently used. Within this scope; Fans who follow spectators, interested teams and athletes on a regular basis, who support positive emotions and support them, and who are tied to their teams with extreme passion, are called fanatical (Koruc et al., 2004).

In other words, the spectator is not only an audience of recreational sports activists, an individual who integrates with sport teams as a supporter of urban ritual (Tasmektepligil et al., 2015), fanatic is a sport that aesthetically who are not interested in beauty, and who do not care about the symbols of their teams in the sickness level (Püsküllüoglu, 2001).

Football lover: It is defined as someone who follows a sporting activity directly or through media and has a special interest and love towards the sport. Likewise, when evaluated in terms of soccer, it is possible to use it to express people who enjoy football, who are interested, who have the pleasure of pursuing football. Among the general characteristics of soccer-loving people is that it is used only to express people who enjoy watching soccer rather than dealing with any team that enjoys watching soccer.

Fans: Words are meant to be a side or a team in an event or sport. It is mostly the name given to sympathizers of soccer teams. In our daily life, politics is also used in the sense of partisan. In football, the crowd is the name given to one of the individuals supporting both teams. Fans show support for the team by supporting them in the form of the team they support (Acet, 2001).

Fanaticism: High sympathy and love is called a concentration on a brand, institution or collective individual. This feeling is given to people who live as fanatic. Extremely fanatical people do not see the right values around them, but instead act only in their own way. Fanaticism, which is not welcomed by some, is supported in many cases. Fanaticism in Turkey; more intensively observed in the field of sports and politics. However, it is called hooliganism if it turns into this aggression and lacks the ability to see the values around it. Fanaticism is an act of love, and hooliganism is the aggressiveness that creates extreme fanaticism (Bahadır, 2006).

For example; are you fan/fanatic? The question is usually answered in terms of football team. Audiences do not show a homogeneous structure in terms of demographic, social, psychological, social and many other aspects. Especially the difference in social and cultural codes is striking.

This separation can be shaped as civilizations (Eastern, Western societies or nations, English, Turks). It is not possible to state that the Turkish soccer audience remembers the same when it is said when it is called English soccer spectator. Basically accepting this differentiation, but claiming that the concepts of audience, fans, fanatic and hooligan are the same, it is difficult for Turkish sports culture.

In terms of consumers of sporting services in general, there are many other concepts (fan, fanatic, hooligan ...). Fans, fanatic, hooligan concepts have different meanings. It will not be the right approach to treat sports fans that are just looking for pleasure and team supporters in the same category as the team's defeat/victory and distressed/rejoicing audience (Unsal, 2005).

Especially some of those watching during the competition are excited; others focus only on the quality of the game, and enjoy the pleasure of the journey. Those who knowingly / unknowingly follow the rules of the game sometimes criticize the referee's decisions or player movements; some are focused on only the points of the goal as they are focused on the score. It's like the beginning phase of a spectator's admiration. For the fans, however, the emotions that victory and defeat create are much more sympathetic.

If the team is defeated, the fans will struggle in the field, feels victorious, or grieved as if they lost their own. So the fans have a much stronger connection with the team than the spectators. The fans are defined as a community that forgets the team after the competition without showing their interest except during the competition time, while the sponsored team refers to the team at every moment in the daily life, not just in sporting events (Dikici, 2008).

In this context, it is possible to reveal the difference of what the audience, supporter, fanatic, hooligan concept evokes, but it is possible to know the details of the concepts, contents and evocations. The differentiation between concepts can be searched first considering the high level of education which fulfills the function of selection in every field of life like Turkey. Because, as the level of education increases, the things that can come to mind about the concept of sport increase (Amman, 2000).

It is of course important how people position themselves in the notion of audience, fan, fanatic, and hooligan. However, knowing the contents of concepts and their connotations will make this position scientific.

\section{Materials and Methods}

This study is based on the basic hypothesis that the opinions of collegiate athletes about the level of soccer/fanatic/fanaticism will be different in terms of various variables; Aims to determine the level of soccer fans / fans / fanatics of university athletes. The study was applied to 438 athletes at Frat University. In order to achieve the 
purpose of the study, the data related to the research were obtained by using literature survey and questionnaire method. Tasmektepligil et al. (FFS) scale developed by the Football Fanaticism Scale (2015); a) Absolutely Participating, b) Participating, c) Participating, and d) Never Participating. According to the developed scale criteria, the total scores of the surveyed respondents on 13 questions were "fanatic" in the range of 13-21, "team supporter" in the interval of 22-30, and "footballer" in the range of 31-52 points. As a result of the reliability analysis (Cronbach's Alpha) conducted to show the internal consistency of the answers given by the viewers to the FFS, the reliability coefficient was found to be 0.87.The results of the Tukey HSD test were used to determine the frequency, percentage, t-test, and one-way analysis of variance (Anova) for multiple groups by SPSS 22 program.

\section{Results}

Table 1. Mean Points Distribution in the Perspective of Foster Independent Variables

\begin{tabular}{llll}
\hline Gender & n & $\%$ & $\begin{array}{l}\text { Average } \\
\text { Score } \overline{\mathrm{X}}\end{array}$ \\
\hline Male & 292 & 66.7 & 40.1575 \\
\hline Woman & 146 & 33.3 & 34.9555 \\
\hline Team and individual sports & & & \\
\hline Team sports & 269 & 61.4 & 36.4535 \\
\hline Individual sports & 169 & 38.6 & 37.0651 \\
\hline Sporting situation & & & \\
\hline Leaving active sport & 240 & 54.8 & 36.7792 \\
\hline Active athlete & 198 & 45.2 & 36.5808 \\
\hline Fanship & & & \\
\hline Fanatic & 106 & 24.2 & 37.7075 \\
\hline Team Supporter & 121 & 27.6 & 36.3719 \\
\hline Football Sever & 211 & 48.2 & 36.3602 \\
\hline Age & & & \\
\hline 20 years and under & 181 & 41.3 & 38.5580 \\
\hline $21-25$ & 192 & 43.8 & 35.2448 \\
\hline $26-30$ & 65 & 14.8 & 35.7538 \\
\hline Total & 438 & 100 & 36.6895 \\
\hline
\end{tabular}

A total of 438 athletes participated in the research. $66.7 \%$ of the respondents were men, $33.3 \%$ were females. When the age range is examined, it is observed that the majority is over 20 years old. Participants were found to be doing all-round sports $(61.4 \%)$ when they looked at the sports branch they did. More than half of the participants (54.8\%) are still actively engaged in sports. The others have already left the sport they were actively involved with. When the level of supporters of the participants is examined, it is found that the highest rate is football with $48.2 \%$.Considering the average score of the participants from FFS, it is in the category of "football lover" with the average score of 40.15 for men, 37.06 for individual sportsmen, 36.77 for active sport lovers, 37.70 for fanatic ones and 36.68 points for overall average of participants (range 31-52 points).

Table. 2 General Average Distributions

\begin{tabular}{lllll}
\hline & $\mathrm{n}$ & Minimum & Maksimum & Mean \\
\hline Average Value & 438 & 13.00 & 52.00 & 36.6895 \\
\hline
\end{tabular}

Participants in the survey; The total score of the answers given over 13 questions; "Fanatic" in the interval of 13-21, "team supporter" in the interval of 22-30, "footballer" in the range of 31-52 points. The general average distribution of students participating in the study is shown on the table. As a result of the analyzes made, it was found out that football fans statistically liked soccer when the average score $(\bar{x}=36.6895)$ they got from the Fanaticism Scale was taken into consideration. 
Table 3. Average of Gender Axis Points of Support Levels

\begin{tabular}{lclllll}
\hline Gender & Gender & $\begin{array}{l}\text { Mean } \\
\text { Score }\end{array}$ & $\begin{array}{l}\text { Standard } \\
\text { Deviation }\end{array}$ & $\mathrm{t}$ & $\mathrm{df}$ & $\mathrm{p}$ \\
Male & 292 & 40.1575 & 9.08708 & 4.843 & 436 & 0.00 \\
Woman & 146 & 34.9555 & 11.27452 & & & \\
\hline
\end{tabular}

The mean scores of males and females were higher than males and the difference was statistically significant $(\mathrm{p}<0.05)$.

Table 4. Average of Sportsman Career Axis Points of Supporters Level

\begin{tabular}{lllllll}
\hline Sporting situation & $\mathrm{n}$ & $\begin{array}{l}\text { Mean } \\
\text { Score }\end{array}$ & $\begin{array}{l}\text { Standard } \\
\text { Deviation }\end{array}$ & $\mathrm{t}$ & $\mathrm{df}$ & $\mathrm{p}$ \\
Leaving active sport & 240 & 36.7792 & 10.70238 & 0.190 & 436 & 0.47 \\
Active athlete & 198 & 36.5808 & 11.08761 & & & \\
\hline
\end{tabular}

There was no significant difference between the active and the active athletes of university students ( $>0.05)$.

Table 5. Average of Team and Individual Sports Axis Points of Fanship Levels

\begin{tabular}{lllllll}
\hline $\begin{array}{l}\text { Team and } \\
\text { individual sports }\end{array}$ & $\mathrm{n}$ & $\begin{array}{l}\text { Mean } \\
\text { Score }\end{array}$ & $\begin{array}{l}\text { Standard } \\
\text { Deviation }\end{array}$ & $\mathrm{t}$ & $\mathrm{df}$ & $\mathrm{p}$ \\
Team sports & 269 & 36.4535 & 11.24302 & -0.573 & 436 & 0.01 \\
Individual sports & 169 & 37.0651 & 10.25922 & & & \\
\hline
\end{tabular}

The difference was considered to be significant $(\mathrm{p}<0.05)$ because the average score of those who performed individual

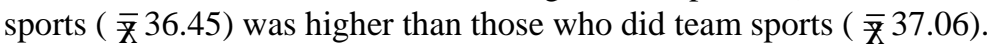

Table 6. Variance analysis and Tukey test according to age axis of fanship levels

\begin{tabular}{llllll}
\hline Anova & & & & & \\
\hline Age & Sum of Squares & df & MeanSquare & $\mathrm{f}$ & Sig. \\
Between groups & 1089.574 & 2 & 544.787 & & \\
Within groups & 50508.197 & 435 & 116.111 & 4.692 & 0.01 \\
Total & 51597.772 & 437 & & & \\
Tukey HSD & & MeanDifference & $\mathrm{p}$ & & \\
& & 3.31322 & $0.00^{*}$ & & \\
20 age and under & $21-25^{*}$ & 2.80416 & 0.17 & & \\
\end{tabular}

The average score of those who are 20 years or younger among the sportsmen are 35.24 in the age range of 21-25 years and $\bar{X}=35.75$ in the age range of 26-30 years. The difference between the mean scores was significant $(\mathrm{p}<0.05)$. When the difference between the age groups was taken into consideration, it is seen that between 20 and 16 years of age and 21-25 years when the Tukey HSD test results are taken into account.

\section{Discussion and Conclusion}

Soccer is a social reality in the world where the macro-transformation process is happening, reaching global dimensions, forming the industry, and drifting behind with visuals and masses.t is possible to make a passive grouping of soccer fans who have gained a universal dimension of audience mass, football fans, supporters and fanatical that cannot be distinguished by certain lines (Karahuseyinoglu et al., 2016).

438 college athletes made the main bulk of the work. In the study aiming to determine the football advocacy levels of university athletes; more than half (54.8\%) of the participants left active sports. When students who participated in my work categorize themselves; $48.2 \%$ of them describe football lovers. Similarly, in Dever's work in 2013, 82.8\% of fans identified themselves as fanatic and $14 \%$ as spectators only (Dever, 2013).Of the 303 detainees and convicts, $35.6 \%$ were supporters, $33.7 \%$ were audiences and $30.7 \%$ were fanatical self-described (Karahuseyınoglu et al., 2016). In another work done; $14.4 \%$ of the subjects participating in the survey are fanatic, $53.2 \%$ are normal and $32.4 \%$ are weak supporters (Celik, Akci, 2016). This situation reinforces the hypothesis that people's team follow-up levels differ.43.3\% of the 707 participants identified themselves as fanatical in a study conducted by Tutkun and his friends on a group of supporters. The rate of those who define themselves moderately is $40.5 \%$ (Tutkun, Tasmektepligil, Canbaz, Acar, \& Con, M. 2012).

The collegiate athletes who tested the main hypothesis of the study were determined according to the scores they received from the fanaticism scale (FFS).The average score obtained in the survey is within the "football lover" limits 
within the scale of "football lover" (31-52 points), team supporter (22-30 points), fanatic (13-21 points) scale ( $\bar{x}=$ 36.68). It was determined that the average score ( $\bar{₹} 26.35)$ was in the level of "team supporters" in a different study on supporters groups (Tasmektepligil, Cankaya, Tunc, 2015). Considering that there are groups of supporters who are going to support the team that is being investigated, "football lover" is expected in this research that includes college athletes.

The athlete has the interest and level of football to take place as soccer fans in the football supporter's scale of the students. When the levels of supporters are gendered; the difference in the mean scores of men was higher than that of women (Table 3).A similar relationship between women and men was found to be significant in a study conducted by Demirel et al. (2007) on the identification of teams with different university students (Demirel et al., 2007). Again, Gullu and Guclu (2006) point out that there is a difference between men and women in the study of the identification of secondary school students with their teams. Men are more "football lovers" than women. This situation reinforces the view that men are more interested in football than women (Apaydın, Giray, \& Amanvermez, 2016).

In this context, research reveals that sport fanatics are predominantly males, but recent research has shown that females are as interested in sport organizations as men (Gantz, Wenner, 1995).

There is no significant relationship between team sponsor levels among colleagues who are currently active in the sport and others. The advocacy levels of collegiate athletes are still actively changing according to whether they are actively doing sports or playing sports. It has not been associated with the release of an athletic link or the active continuation of the association.

When the participants were divided into team sports and individual sports as supporters, it was seen that the level of supporters of individual sports were higher than those who played team sports. Being playing individual and team sports also cause the level of support to change.

The majority of participants are over 20 years old. It is possible to reach different results in different studies. In studying what Arslan did; the majority of soccer spectators were seen to be between 15 and 30 years old and male audience (Arslan, 1997). Dogan and Moral have also reported that 47.94\% of footballers are in the 16-20 age groups (Dogan, Moral1, 1999). On the other hand, Mercil and Akyol found that the highest participation group was in the 25-34 age groups with 27.5\% (Mercil, Akyol, 2004). It is concluded that the age categories of the athletes have a decisive influence on the supporter's level (Table 6).It has been seen that among the age groups, the students of the athletes under the age of 20 have a different level of supporters than the students up to the age of 25.However, studies have not been found to determine age in the literature. The fact that football supporters are examined, majority of them are between the ages of 17-29, and that the study participated by 600 students is not determinant in the level of soccer fanship (Demirel et al.2007).

\section{References}

Acet, M. (2001). Social factors that make football spectators fanatical and aggressive. Unpublished PhD thesis, Gazi University Institute of Health Sciences Physical Education and Sports Department, Ankara.

Amman, M. T. (2000). Sport Sociology, Sports in Social Sciences, Istanbul: Alfa Publications, First Edition, September.

Apaydın, F., Giray, D. Ö. C., \& Amanvermez, İ. (2016). An Empirical Study on the Examination of the Attitudes of Women Who Have a Target Group for Football Clubs in the Stadiums.

Appelbaum, L. G., Cain, M. S., Darling, E. F., Stanton, S. J., Nguyen, M. T., \& Mitroff, S. R. (2012). What is the identity of a sports spectator, 52(3), 422-427.

Arslan, C., Bingölbalı, A., \& Ramazanoglu, F. (1997). Motivational and Psychological Factors Influencing Soccer Sense to Become Fanatic. Hacettepe University Football Science and Technology Journal, 6, 3-10.

Bahadir, Z. (2006). The Effect of the Socio-Cultural Structure of Football Spectators on the Act of Violence Higher Education Thesis. Nigde University, Institute of Social Sciences. Nigde.

Cakır, V. O., \& Korkmaz, S. (2015). Football Cheers in the Context of Music and Movement. International Journal of Science, Culture and Sport, 3, 845-857.

Celik, M., \& Akci, Y. (2016). Football Supporter and Institutional Relations Review. Electronic Journal of Social Sciences, 15, 58.

Demirel, M., Karahan, G. M., \& Famous, H. (2007). Levels of Identification of Sports Fans of Different Universities by Teams Nigde University, Journal of Physical Education and Sport Sciences, 1(2).

Dever, A. (2013). Industrial Football and Supporters: The Case of Kayseri Province. Cumhuriyet University Social Sciences Institute Department of Sociology Department of Sociology Dept. Sivas. 
Dikici, S. T. (2008). Social and Political Profiles of Fans in Turkey: Besıktas JK Bazaar Group Example. Kocaeli University, Institute of Social Sciences, Master Thesis.

Dogan, B., \& Moral1, S. (1999). Spectator Exaggerations in Football and the Psycho-social Reasons Behind it, Football Science Magazine, Hacettepe University, Year 6, p. 16-20, Ankara.

Eker, G. Ö. (2010). Irresistible Charming Of the Football, Portrait of Fascinated Supporter, Fanaticism and Besıktas. National Folklore Magazine, 22(85), 173-183.

Gantz, W., \& Wenner, L. A. (1995). Fanship And The Television Sports Viewing Experience. Sociology of Sport Journal, 12(1), 56-74. https://doi.org/10.1123/ssj.12.1.56

Gullu, M., \& Güclü, M. (2006). An Investigation of Identification of Secondary School Students with Sports Teams. 9th International Sports Science Congress Proclamation Book. 3-5 November, Mugla, 686-689.

Karahuseyınoglu, M. F., Kırtepe, A., Gacar, A., \& Karahüseyinoğlu, F. (2016). Football Tracking Levels of, Detainees and Prisoners. Journal of Sport and Performance Studies, 7(2), 121-126.

Koruc, Z., Bayar, P., \& Arslan. (2004). Football fanatics in Turkey: Social identity and violence. Turkish Football Association Foundation Ankara Branch and General Directorate of Sport Toto Reasons for Terrorism in Football Competitions and Prevention Ways Scientific Research Contest, Ankara.

Mercil, I., \& Akyol, F. (2004). Ethical and emotional identification of Turkish football fans with their clubs, Galatasaray University, Turkey National Olympic Committee and Center International Sport, Justice, Ethics and Sports Seminar, Istanbul, April.

Püsküllüoglu, A. (2001). Dictionary of Foreign Words in Turkic. 2nd Edition. Friend Publications. Ankara.

Tasmektepligil, M. Y., Cankaya, S., \& Bronze, T. (2015). Funny fanaticism scale. Journal of Sport and Performance Studies, 6(4), 41-49.

Tutkun, E., Tasmektepligil, M. Y., Canbaz, S., Acar, H., \& Con, M. (2012). Social and Economic Characteristics of Samsun Sports Fans and Trends in Violence. Selcuk University Journal of Physical Education and Sport, 14(1), $56-63$.

Unsal, A. (2005). Tribune community fires: violence in commercialized Turkish football. Communication, 2005.

\section{Copyrights}

Copyright for this article is retained by the author(s), with first publication rights granted to the journal.

This is an open-access article distributed under the terms and conditions of the Creative Commons Attribution license which permits unrestricted use, distribution, and reproduction in any medium, provided the original work is properly cited. 